Available online at http://jurnal.goretanpena.com/index.php/JSSR

\title{
SISTEM KENDALI JARAK JAUH ROBOT PEMADAM API DENGAN MENGGUNAKAN SENSOR FLAM DAN SENSOR MQ BERBASIS MOTOR POMPA
}

\author{
Muhammad Amin ${ }^{1}$, Ricki Ananda ${ }^{2}$ \\ STMIK Royal, Kisaran \\ e-mail: stmikroyal13@gmail.com
}

\begin{abstract}
Fire is an emergency caused by flammable objects and can also be caused by short circuits that can endanger human life, property, objects and the surrounding environment. Factors that occur because of human fires, in the form of forest burning, littering of cigarette butts to the lack of public awareness. Like CV Rifanta Tanjungbalai which only uses water as an anticipation of firefighting. Based on this, the researcher will design a fire fighting robot that has several inputs from electronic modules such as gas readers, fire readers, up to heat readers. In addition, the output of the robot that will be designed uses a dc motor as a fire extinguisher fan that functions as a small-scale fire extinguisher such as cigarette butts, sparks from matches. The pump motor is also used as a fire extinguisher. When the robot car detects a source of fire or gas leaks up to an increase in temperature, the robot will turn on a buzzer to notify people around that there is a potential fire hazard. The control system for the prototype robot uses the HC-05 interface module which is connected to Android.
\end{abstract}

Keywords: Robot Fire Extinguisher, Tebing Tinggi Station, Fire Sensor

\begin{abstract}
Abstrak: Kebakaran adalah suatu keadaan darurat yang disebabkan oleh benda yang mudah terbakar dan dapat juga disebabkan karena arus pendek yang dapat membahayakan jiwa manusia, harta, benda dan lingkungan sekitar. Faktor terjadinya kebakaran karena manusia, berupa pembakaran hutan, membuang puntung rokok sembarangan sampai dengan kurang kesadaran masyarakat. Seperti CV Rifanta Tanjungbalai yang hanya menggunakan air sebagai antisipasi pemadam kebakaran. Berdasarkan hal tersebut peneliti akan merancang robot pemadam api yang memiliki beberapa input dari modul elektronika seperti pembaca gas, pembaca api, sampai dengan pembaca suhu panas. Selain itu output dari robot yang akan dirancang menggunakan motor dc sebagai kipas pemadam api yang difungsikan sebagai pemadam api skala kecil seperti puntung rokok, percikan api yang berasal dari korek api. Adapun motor pompa yang juga digunakan sebagai pemadaman api. Ketika mobil robot mendektesi adanya sumber api atau kebocoran gas sampai dengan peningkatan suhu, maka robot tersebut akan menyalakan buzzer untuk memberi tahu orang sekitar bahwa adanya potensi bahaya kebakaran. Untuk sistem kendali prototype robot menggunakan modul interface hc-05 yang dihubungkan dengan android.
\end{abstract}

Kata kunci : Robot Car, Fire Sensor, CV Rifanta Tanjungbalai

\section{PENDAHULUAN}

Kebakaran merupakan hal yang umum terjadi dikarenakan faktor alam ataupun karena tangan manusia, adapun kondisinya seperti: petir, gempa bumi, gunung meletus, panas matahari, banjir dan tanah longsor. Sebagaiamana diketahui faktor terjadinya kebakaran karena perbuatan manusia adalah berupa pembakaran hutan, membuang puntung rokok sembarangan sampai dengan kurang kesadaran atau melanggar aturan yang 
Available online at http://jurnal.goretanpena.com/index.php/JSSR

telah di tetapkan. Seperti yang terjadi di CV Rifanta Tanjungbalai yang hanya menggunakan air sebagai antisipasi pemadam kebakaran.

Untuk mengatasi hal tersebut, maka dalam penelitian ini merancang robot pemadam api, robot menggunakan modul interface hc-05 yang dihubungkan dengan android, hal ini di karenakan penggunaan jaringan Bluetooth jauh lebih efektif jika menggunakan jaringan internet yang pengiriman datanya perbyte/detik.

\section{Robot}

Robot berasal dari bahasa Cheko, "Robota" yang berarti pekerja atau kuli yang tidak mengenal rasa lelah ataupun bosan. Tugas-tugas yang dilakukan oleh robot biasanya pekerjaan yang berulang, kotor, berat, dan berbahaya Robot merupakan alat mekanik yang diciptakan untuk meringankan pekerjaan manusia. Robot sendiri memiliki beberapa jenis dan fungsi. Hal tersebut tergantung pada program yang ditanamkan dalam dirinya (Pram, 2015).

\section{Arduino}

Arduino adalah kit elektronik atau papan rangkaian elektronik open source yang di dalamnya terdapat komponen utama yaitu sebuah chip mikrokontroler dengan jenis AVR dari perusahaan Atmel. Tujuan dari adanya mikrokontroler untuk membaca input dengan memprosesnya hingga menimbulkan output. Dari adanya Mikrokontroler, ini dapat ditemukan pada berbagai alat seperti handphone, MP3 player, DVD, televisi, AC dan masih banyak lagi (M.Syahwil, 2015).

\section{Motor servo}

Motor servo adalah sebuah motor DC dengan sistem umpan balik tertutup di mana posisi rotornya akan diinformasikan kembali ke rangkaian kontrol yang ada di dalam motor servo. Motor ini terdiri dari sebuah motor DC, serangkaian gear, potensiometer, dan rangkaian kontrol. Potensiometer berfungsi untuk menentukan batas sudut dari putaran servo. Sedangkan sudut dari sumbu motor servo diatur berdasarkan lebar pulsa yang dikirim melalui kaki sinyal dari kabel motor (Abdul Kadir, 2016).

\section{Bluetooth he-05}

Modul Bluetooth HC-05 merupakan salah satu modul Bluetooth yang dapat ditemukan dipasaran dengan harga yang relatif murah. Modul Bluetooth HC-05 terdiri dari 6 pin konektor, yang setiap pin konektor memiliki fungsi yang berbeda beda. Selain itu HC-05 merupakan sebuah modul Bluetooth SPP (Serial Port Protocol) yang mudah digunakan untuk komunikasi serial wireless (nirkabel) yang mengonversi port serial ke BluetoothHC05 menggunakan modulasi bluetooth V2.0 + EDR (Enchanced Data Rate) 3 Mbps dengan memanfaatkan gelombang radio berfrekuensi 2,4 GHz (Abdul Kadir, 2014).

\section{Motor dc}

Motor Listrik DC atau DC Motor adalah suatu perangkat yang mengubah energi listrik menjadi energi kinetik atau gerakan (motion). Motor DC ini juga dapat disebut sebagai Motor Arus Searah. Seperti namanya, DC Motor memiliki dua terminal dan memerlukan tegangan arus searah atau DC (Direct Current) untuk dapat menggerakannya. Motor Listrik DC ini biasanya digunakan pada perangkatperangkat Elektronik dan listrik yang menggunakan sumber listrik DC seperti Vibrator Ponsel, Kipas DC dan Bor Listrik DC.

\section{Driver 1298d}

L298 adalah jenis IC driver motor yang dapat mengendalikan arah putaran dan kecepatan motor DC ataupun Motor stepper. Mampu mengeluarkan output tegangan untuk Motor DC dan motor stepper sebesar 50 volt. IC 1298 terdiri 
Available online at http://jurnal.goretanpena.com/index.php/JSSR

dari transistor-transistor logik (TTL) dengan gerbang NAND yang memudahkan dalam menentukkan arah putaran suatu motor dc dan motor stepper. Dapat mengendalikan 2 untuk motor DC namun pada hanya dapat mengendalikan 1 motor stepper.

\section{Sensor api (Flame)}

Sensor ini dapat mendeteksi nyala api dalam rentang panjang gelombang 760 $\mathrm{nm} 1100 \mathrm{~nm}$, seperti ditunjukkan pada Gambar 2.11. Sensor ini dapat mendeteksi suhu panas berkisar $25^{\circ} \mathrm{C}-85^{\circ} \mathrm{C}$. Sensor ini dapat mendeteksi api dari jarak 100 $\mathrm{cm}$ dengan keluaran tegangan sebesar 0,5 $\mathrm{V}$, dan pada jarak $20 \mathrm{~cm}$ dengan objek sensor ini dapat mengeluarkan keluaran tegangan sebesar 5 V (Dodoon, 2017).

\section{Sensor gas}

MQ-2 merupakan sensor gas yang digunakan dalam peralatan untuk mendeteksi gas karbon monoksida (CO) dalam kehidupan sehari-hari, industri, atau mobil. Fitur dari sensor gas MQ-2 ini adalah mempunyai sensitivitas yang tinggi terhadap karbon monoksida (CO), stabil, dan berumur panjang. Sensor ini menggunakan catu daya heater $5 \mathrm{~V}$ AC/DC dan menggunakan catu daya rangkaian 5 VDC, jarak pengukuran $20-$ 2000 PPM untuk mampu mengukur gas karbon monoksida (Fendi Ardiansyah, 2017).

\section{Buzzer}

Buzzer adalah sebuah komponen elektronika yang berfungsi untuk mengubah getaran listrik menjadi getaran suara. Perangkat elektronika ini terbuat dari elemen piezoceramics yang diletakkan pada suatu diafragma yang mengubah getaran/vibrasi menjadi gelombang suara. Buzzer menggunakan resonansi untuk memperkuat intensitas suara.

\section{Arduino ide}

Arduino IDE (Integrated

Development Environment) adalah software yang di gunakan untuk memprogram di arduino, dengan kata lain Arduino IDE sebagai media untuk memprogram board Arduino. Arduino IDE bisa di download secara gratis di website resmi Arduino IDE.

Arduino IDE ini berguna sebagai text editor untuk membuat, mengedit, dan juga mevalidasi kode program. bisa juga digunakan untuk meng-upload ke board Arduino. Kode program yang digunakan pada Arduino disebut dengan istilah Arduino "sketch" atau disebut juga source code arduino, dengan ekstensi file source code .ino

\section{METODE}

Metode Penelitian yang dipakai adalah Metode Penelitian Deskriptif sebagai prosedur pemecahan masalah yang dilakukan dengan cara menggambarkan keadaan subjek atau objek dalam penelitian dapat berupa orang, lembaga, masyarakat, dan yang lainnya yang pada saat sekarang berdasarkan fatka-fakta yang tampak atau apa adanya.

\section{HASIL DAN PEMBAHASAN}

\section{Analisis Konfigurasi Sistem}

Adapun sistem yang berjalan di CV Rifanta Tanjungbalai, diantaranya:

1. Penggunaan air merupakan pengaman pertama yang dilakukan oleh pegawai CV Rifanta Tanjungbalai.

2. CV Rifanta Tanjungbalai tidak dilengkapi dengan sensor pendeteksi api maupun pendeteksi asap.

3. Lokasi Pemadam jauh CV Rifanta Tanjungbalai. 
Available online at http://jurnal.goretanpena.com/index.php/JSSR

\section{Analisis Perangkat Keras (Hardware)}

Hardware atau perangkat keras yang digunakan pada penelitian ini untuk membentuk alat adalah :

Tabel 1. Perangkat Keras yang Digunakan Pada Penelitian

\begin{tabular}{|c|c|c|c|}
\hline Hardware & Spesifikasi & Jumlah & Fungsi \\
\hline Laptop & $\begin{array}{c}\text { Lenovo } \\
\text { B450 }\end{array}$ & 1 & Penulis perintah \\
\hline Controller & $\begin{array}{l}\text { Arcluing } \\
\text { nane }\end{array}$ & 1 & Penulis perintah \\
\hline Servo & SE90 GI & 2 & Pengerala selang \\
\hline Ic driver & L298 & 1 & Pengatur motor \\
\hline batergi & 18650 & 4 & Supply togangan \\
\hline Motor de & $5 \mathrm{VDC}$ & $\begin{array}{c}2 \text { motor } \\
\text { de } \\
1 \text { Rempas }\end{array}$ & 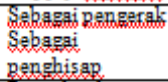 \\
\hline Selang & $1 / 2 \mathrm{~cm}$ & $2 \mathrm{~m}$ & Pengalir aliran air \\
\hline Soder. & Deco & 1 & Pelekat timah \\
\hline Renghisap & Deco & 1 & Penghisag timgh \\
\hline Minyale & Deco & 1 & Pemanas timah \\
\hline jumper & $10 \mathrm{pin}$ & 1 meter & jumper \\
\hline Sensor & $\begin{array}{c}\text { Flame } \\
\text { mq. }\end{array}$ & $\begin{array}{l}1 \\
1\end{array}$ & $\begin{array}{l}\text { Pembacs api } \\
\text { Pembaca gas }\end{array}$ \\
\hline Batergi & 18650 & 4 & Supply tegangan \\
\hline
\end{tabular}

\section{Analisis Perangkat Lunak (Software)}

Software atau perangkat lunak yang digunakan pada penelitian ini untuk membentuk alat adalah :

Tabel 2. Perangkat Keras

\begin{tabular}{|c|c|l|}
\hline Software & Keterangan & \multicolumn{1}{c|}{ Fungsi } \\
\hline Windows 7 & Sistem operasi & $\begin{array}{l}\text { Menjalankan sistem } \\
\text { operasi }\end{array}$ \\
\hline Arduino.ide & $\begin{array}{c}\text { Pemrogram } \\
\text { controller }\end{array}$ & Menulis penintah \\
\hline $\begin{array}{c}\text { Microsoft } \\
\text { word }\end{array}$ & $\begin{array}{c}\text { Pemrograman } \\
\text { penulisan } \\
\text { proposal }\end{array}$ & $\begin{array}{l}\text { Membuat laporan } \\
\text { skripsi }\end{array}$ \\
\hline
\end{tabular}

\section{Perancangan Sistem Secara Umum}

Fungsi perancangan sistem secara umum berfungsi untuk mengetahui gambaran dari cara kerja sistem atau rancangan alat serta prinsip kerjanya dilapangan.

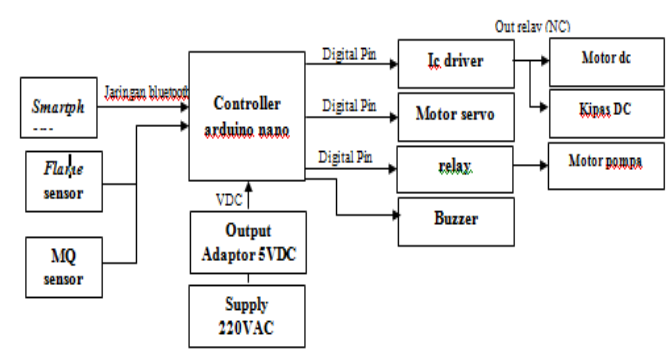

\section{Gambar 1. Block Diagram Secara Umum}

Pengujian Keseluruhan

Pengujian keseluruhan bertujuan apakah sistem kendali mobil robot pemadam api bekerja sesuai dengan perintah atau tidak. Selain itu pengujian sensor juga dibuktikan dengan mematikan sistem kendali, atau mobil robot dalam keadaan diam, tetapi kondisi menyala (dialiri tegangan).

\section{Tabel 3. Pengujian Keseluruhan Beban}

\begin{tabular}{|c|c|c|c|c|}
\hline Perintaly & $\begin{array}{l}\text { Re } \\
\text { lay }\end{array}$ & Servo & Interface & Motor \\
\hline HIGH I & Nc & $0^{\circ}$ & connected & Pompa Altif \\
\hline LOW 1 & No & $0^{\circ}$ & connected & Pompa Xlati \\
\hline HIGH 2 & No & $0^{\circ}$ & connected & $\begin{array}{c}\text { Motor de } 12 \\
\text { altif. }\end{array}$ \\
\hline HIGH 3 & No & $0^{\circ}$ & connected & $\begin{array}{c}\text { Motor do } 12 \\
\text { berlawangn gah }\end{array}$ \\
\hline HIGH 3 & No & $0^{\circ}$ & connected & Motor de l agtif \\
\hline HIGH 4 & No & $0^{\circ}$ & connected & Motor de 2 geff \\
\hline SLIDE I & No & $0^{\circ}-180^{\circ}$ & connected & Senvo I aktif \\
\hline SLIDE2 & No & $0^{\circ}-180^{\circ}$ & connected & Servo 2 aktif \\
\hline
\end{tabular}

Pada tabel 3 diatas menjelaskan tentang sistem kerja mobil robot pemadam api, dimana sistem kerja mobil robot ketika slide 1 dan slide 2 digerakan, maka motor servo akan mengarahkan selang penyiram air ke api, sementara untuk data $H I G H 1$ sampai $H I G H 4$ atau button 1 sampai button 4 mengirimkan data untuk mengaktifkan output berupa motor pompa, sampai dengan sistem kendali mobil robot.

Sementara untuk tabel pengujian sensor ditunjukan pada tabel 5.8 dibawah.

Tabel 4. Pengujian Sensor

\begin{tabular}{|c|c|c|}
\hline Tegangan & Data & Keterangan \\
\hline \multirow{4}{*}{$\begin{array}{l}5 \mathrm{VDC} / \\
\text { Intemal }\end{array}$} & $1 \mathrm{~B}$ & $\begin{array}{l}\text { Tidak mendeteksi } \\
\text { api }\end{array}$ \\
\hline & $0 \mathrm{~B}$ & Mendeteksi api \\
\hline & $\begin{array}{l}0-400 \\
\mathrm{ADC}\end{array}$ & Tidak ada asap \\
\hline & $\begin{array}{l}401- \\
1023 \\
\mathrm{ADC}\end{array}$ & $\begin{array}{l}\text { Mendeteksi asap } \\
\text { atau gas }\end{array}$ \\
\hline
\end{tabular}


Available online at http://jurnal.goretanpena.com/index.php/JSSR

Pada tabel 4 menampilkan informasi bahwa kondisi 0 pada sensor flame menyatakan kondisi tidak mendeteksi api, sedangkan kondisi 1 pada sensor flame menyatakan kondisi ada api. Sehingga pada saat kondisi ada api, maka menimbulkan gas atau asap, dan nilai pembacaan sensor MQ berada pada range 401 ADC sampai dengan 1023 ADC.

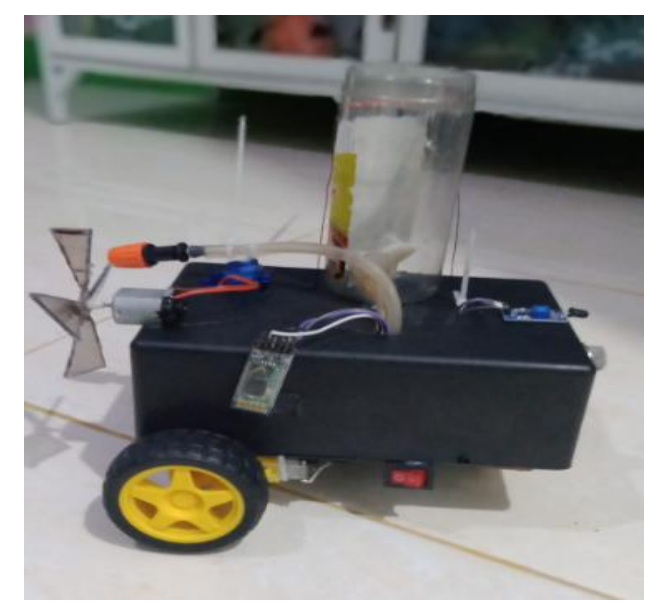

\section{Gambar 2. Rancangan Alat}

Pada gambar 2 diatas menampilkan rancangan alat yang sudah ada, dimana sistem kerja dari rancangan robot tersebut, bisa menyiramkan air dan menyalakan kipas yang bertujuan untuk mematikan lampu.

\section{SIMPULAN}

1. Sistem kendali rancangan alat mampu mengirimkan data sejauh 10 meter, dan jika prototype robot pemadam api diaplikasikan, maka interface hc-05 dalam mengirimkan data.

2. Daya pompa hanya dapat melakukan penyiraman air skala kecil.

3. Hasil dari penelitian ini memberikan pencegahan kebakaran skala kecil yang di kontrol melalui android.

\section{DAFTAR PUSTAKA}

Abdul. K. Buku pintar pemrograman arduino. 2016. Mediakom. Yogyakarta.

Akhmad Z. Unggul, W., Eka, M. (2015) Implementasi bluetooth HC-05 untuk memperbarui informasi pada perangkat running text berbasis android. Jurnal EECCIS

Agung, R.P. Andi, S (2016) Perancangan dan implementasi robot pemadam api berbasis mikrokontroller arduino mega 2560. Universitas respati Indonesia.

Mahera (2015) Rancang bangun system control pemakai listrik secara multi channel berbasis arduino(Studi kasus kantor LBH banda Aceh). Jurnal online teknik elektro. Vol 2 no 2. E-ISSN : 2252-7036

Muhammad, I. Solekhan (2015) Perancangan wheel mobile robot sebagai modul praktikum mikrokontroller. Jurnal simetris. Vol 4. No 1. ISSN: 2252-4983

Muhammad.S 2015. Panduan Mudah Simulasi dan Praktik Mikrokontroler Arduino. Yogyakarta : ANDI

Nazir (2015) Saklar otomatis berbasis (light dependent resistor (LDR) pada mikrokontroller arduino uno. e-ISSN : 2476-9398

Purnomo.D (2017) Model prototyping pada pengembangan sistem informasi. Jurnal informatika merdeka pasuruan. Vol 2. No 2. 2017. ISSN 2503-1945

Rachmadani,, Muhammad, Y (2016) Sistem robot pemadm api berkaki berbasis arduino pada kontes robot pemadam api Indonesia 2016. DOI : 10.210009/autocrzy 04.015

Sumiati. Sigit.S (2017) Prototype robot pemadam api menggunakan fuzzy inference systems berbasis mikrokontroller Avr Atmega 328. Jurnal penelitian dan pengabdian masyarakat. 
Available online at http://jurnal.goretanpena.com/index.php/JSSR

Suprapto. Iwan. S (2018) Rancang bangun robot mobil pemadam api berbasis mikrokontroller at89s51. Jurusan teknik elektro. Universits diponegoro.

Utsman ali (2015) Rancang bangun alat penjual minuman kopi otomatis menggunakan RFID (Radio frekuensi identification) berbasis arduino. Seminar hasil teknik elektro S1 ITN Malang.

Wiwik (2015) Prototipe controller lampu penerangan led independent bertenaga surya. Jurnal Gamma. ISSN 2086-3071

Yurindra (2015) Pengontrol alat penyiram tanaman otomatis menggunakan sms berbasis mikrokontroller ic atmega 16. Jurnal sisfokom. Vol 3. No 1. 